\title{
Reducing dropout of contact lens wear with Biotrue multipurpose solution
}

This article was published in the following Dove Press journal:

Clinical Ophthalmology

24 January 2014

Number of times this article has been viewed

\section{Marjorie J Rah \\ Mohinder M Merchea \\ Marianne Q Doktor}

Bausch \& Lomb Incorporated, Rochester, NY, USA
Correspondence: Marjorie J Rah Bausch \& Lomb Incorporated, I 400 North Goodman St, Rochester, NY 14609, USA

$\mathrm{Tel}+\mathrm{I} 5854136397$

Fax +I 5853380750

Email marjorie.rah@bausch.com
Purpose: To evaluate whether the use of Biotrue multipurpose solution (MPS) could significantly reduce the likelihood with which patients drop out of using daily wear contact lenses (CLs) amongst 18-44-year-old frequent replacement CL wearers.

Methods: Daily wear CL subjects habitually using MPSs (other than Biotrue MPS) who reported an intent to imminently drop out of CL wear because of comfort and dryness complaints were recruited to participate in this investigation. Subjects were switched to Biotrue MPS and continued to use habitual CL types with the new MPS for 2 weeks. Subjects completed an online satisfaction questionnaire at baseline and after 2 weeks to assess the change in symptoms and the intent to drop out of CL wear. Six months after completion of the initial study, a follow-up survey was administered to a subset of the initial participants.

Results: A total of 153 daily wear (silicone hydrogel and hydrogel) subjects completed this 2-week study with Biotrue MPS. When measuring those with the highest propensity to drop out of lens wear ( $\mathrm{n}=93$ ) after switching to Biotrue MPS, 90\% of subjects significantly reduced their likelihood of dropping out of $\mathrm{CL}$ wear $(P<0.0001)$. Online interviews were conducted with 73 of the study participants 6 months after completion of the initial study. A total of $93 \%$ of participants responded that they were still wearing CLs at least once per week. Of the $7 \%$ of respondents who were not currently wearing lenses 6 months after the initial study, two had dropped out of lens wear completely, and three still wore lenses less than once per week.

Conclusion: Patients intending to drop out of CL wear due to discomfort and dryness significantly reduced their propensity of discontinuing lens wear following use of Biotrue MPS. Six months after completion of the study, 93\% of patients were still wearing CLs at least once per week.

Keywords: multipurpose solution, contact lens, dropout

\section{Introduction}

Symptoms of dryness and discomfort are often cited as major factors related to the discontinuation of contact lens wear. ${ }^{1-8}$ Dropout rates reported in the literature range from $15.9 \%-34 \%{ }^{1,5,8,9}$ Despite the innovation of contact lens materials for daily wear/ frequent replacement (ie, silicone hydrogels), the contact lens dropout rates have not changed over time.

Contact lens discontinuation has been identified as a contributing factor to stagnant lens growth. ${ }^{4,8}$ However, it also has been reported that lapsed contact lens wearers can be successfully refitted with contact lenses, ${ }^{4,7,10}$ and that the selection of contact lens material, design, replacement frequencies, and care systems can lead to continuation of contact lens wear. ${ }^{4,8,9}$ 
The purpose of this study was to evaluate whether use of Biotrue multipurpose solution (MPS) (Bausch \& Lomb Incorporated, Rochester, NY, USA) could significantly reduce a patient's likelihood of dropping out of the daily wear contact lens category amongst 18-44-year-old frequent replacement contact lens wearers.

\section{Methods}

Participants were recruited by Kadence International (Boston, MA, USA), an online panel database of consumers who volunteered to take part in online surveys. Daily wear contact lens patients habitually using MPSs (other than Biotrue MPS) who reported their intent to imminently drop out of contact lens wear because of comfort and dryness complaints were recruited to participate in this investigation. To take part in the research, participants needed to meet the following criteria:

- Soft contact lens wearers who displayed a likelihood to drop out of the daily wear contact lens category;

- Close to dropping out of contact lens wear for selfreported comfort and/or dryness reasons;

- Between the ages of 18-44 years old;

- Been wearing lenses for at least 7 months;

- Must use multipurpose lens solution;

- Never used Biotrue MPS.

Following enrollment, subjects were provided with Biotrue MPS and asked to continue to use their habitual contact lens types with the new MPS for 2 weeks. Subjects were directed to follow the instructions on the package regarding proper use of the solution. Subjects completed an online satisfaction questionnaire at baseline and after 2 weeks of Biotrue MPS use. The questionnaire utilized a standard agree/ disagree, 6-point Likert scale to assess patients' changes in symptoms and their intent to drop out of contact lens wear. A statistical analysis comparing pre- versus post-trial subject responses was performed using a nonparametric Wilcoxon's signed-rank test.

Six months after completion of the initial study, a followup survey was administered. The initial phase did not require that respondents participate in the 6-month follow-up; however, all participants in the initial phase were invited to participate. The follow-up was conducted to determine whether the participants had discontinued contact lens wear and if not, whether they continued the use of Biotrue MPS following the initial phase of the study.

The initial phase of this research was conducted from May 15, 2012 through July 22, 2012. The 6-month follow-up was conducted from January 1, 2013 through January 15, 2013.

\section{Results}

\section{Initial study results}

A total of 153 daily wear (silicone hydrogel and hydrogel) contact lens wearers completed this 2-week study with Biotrue MPS. Of the 153 lens wearers enrolled, only those with the highest propensity for discontinuation of lens wear ("slight chance", "probably", or "definitely will stop") were included in this report $(n=93)$. Those who stated their likelihood to drop out as "might/might not stop" were not included in the analysis. The patient demographics for the full sample and the subset used for this report are listed in Table 1. The data on

Table I Subject demographics

\begin{tabular}{|c|c|c|c|}
\hline & $\begin{array}{l}\text { Full study } \\
\text { sample } \\
(n=\mid 53)\end{array}$ & $\begin{array}{l}\text { Subset of } \\
\text { respondents } \\
(n=93)\end{array}$ & $\begin{array}{l}\text { Six-month } \\
\text { follow-up } \\
(n=73)\end{array}$ \\
\hline \multicolumn{4}{|l|}{ Sex } \\
\hline Male & $35 \%$ & $39 \%$ & $29 \%$ \\
\hline Female & $65 \%$ & $61 \%$ & $71 \%$ \\
\hline \multicolumn{4}{|l|}{ Age } \\
\hline Mean age & 32 years & 32 years & 32 years \\
\hline $35-44$ years & $32 \%$ & $37 \%$ & $29 \%$ \\
\hline $25-34$ years & $58 \%$ & $55 \%$ & $62 \%$ \\
\hline 18-24 years & $10 \%$ & $9 \%$ & $10 \%$ \\
\hline \multicolumn{4}{|l|}{ Household income } \\
\hline$\$ 125,000$ or more & $14 \%$ & $18 \%$ & $14 \%$ \\
\hline$\$ 100,000-\$ 124,999$ & $18 \%$ & $20 \%$ & $19 \%$ \\
\hline$\$ 75,000-\$ 99,999$ & $20 \%$ & $18 \%$ & $16 \%$ \\
\hline$\$ 50,000-\$ 74,999$ & $23 \%$ & $23 \%$ & $23 \%$ \\
\hline$\$ 25,000-\$ 49,999$ & $22 \%$ & $18 \%$ & $23 \%$ \\
\hline Less than $\$ 25,000$ & $3 \%$ & $2 \%$ & $4 \%$ \\
\hline \multicolumn{4}{|l|}{ Race/ethnicity } \\
\hline White or Caucasian & $75 \%$ & $76 \%$ & $74 \%$ \\
\hline Asian or Asian & $9 \%$ & $9 \%$ & $12 \%$ \\
\hline \multicolumn{4}{|l|}{ American } \\
\hline Black or African & $7 \%$ & $5 \%$ & $7 \%$ \\
\hline \multicolumn{4}{|l|}{ American } \\
\hline Hispanic or Latino & $6 \%$ & $5 \%$ & $4 \%$ \\
\hline Other & $3 \%$ & $4 \%$ & $3 \%$ \\
\hline \multicolumn{4}{|l|}{ Level of education } \\
\hline $\begin{array}{l}\text { Advanced graduate } \\
\text { work or PhD }\end{array}$ & $9 \%$ & $5 \%$ & $13 \%$ \\
\hline Masters degree & $23 \%$ & $26 \%$ & $20 \%$ \\
\hline Some graduate work & $7 \%$ & $8 \%$ & $4 \%$ \\
\hline $\begin{array}{l}\text { Four-year college } \\
\text { degree }\end{array}$ & $34 \%$ & $35 \%$ & $35 \%$ \\
\hline $\begin{array}{l}\text { Two-year college } \\
\text { degree }\end{array}$ & $4 \%$ & $5 \%$ & $7 \%$ \\
\hline $\begin{array}{l}\text { Some college, } \\
\text { but did not graduate }\end{array}$ & $19 \%$ & $21 \%$ & $17 \%$ \\
\hline High school graduate & $3 \%$ & $1 \%$ & $4 \%$ \\
\hline \multicolumn{4}{|l|}{ Region } \\
\hline West & $22 \%$ & $24 \%$ & $23 \%$ \\
\hline Midwest & $22 \%$ & $18 \%$ & $23 \%$ \\
\hline Northeast & $23 \%$ & $23 \%$ & $23 \%$ \\
\hline South & $34 \%$ & $35 \%$ & $30 \%$ \\
\hline
\end{tabular}

Abbreviations: $\mathrm{n}$, number; $\mathrm{PhD}$, doctor of philosophy. 
habitual lens brands worn and lens care systems used are provided in Figures 1 and 2. Within the subset of patients, $39 \%$ of subjects reported using the Opti-Free family of solutions (Alcon Laboratories, Fort Worth, TX, USA) and 21\% wore ACUVUE OASYS (Johnson \& Johnson Vision Care, Jacksonville, FL, USA) silicone hydrogel lenses habitually.

Of the 93 subjects included in the analysis, $80 \%$ reduced their likelihood to discontinue contact lens wear after using Biotrue MPS for 2 weeks (post-study, they reported that they "probably" or "definitely will not stop"). The nonparametric Wilcoxon's signed-rank test comparing pre- versus post-trial subject responses showed a statistically significant reduction in participants' propensity to drop out of contact lens wear post-trial $(P<0.0001)$. In order to be considered as reduced likelihood to drop out, subjects had to move at least one level on the six-point scale of propensity to drop out from pre-trial to post-trial (for example, from "slight chance I might stop" to "might/might not stop") (Table 2). The percentage of subjects who lowered their propensity for discontinuing contact lens wear, as indicated by the number of levels lowered, are provided in Figure 3. Fifty-one percent (51\%) of these subjects shifted to "definitely will not stop" wearing contact lenses after use of Biotrue MPS. Among the 84 subjects whose level of propensity changed after the study, $88 \%$ reduced their likelihood of discontinuing lens wear to "definitely not" or "probably not." The reduced likelihood to discontinue lens wear was also significant for the 84 subjects whose level of propensity changed after the study $(P<0.0001)$.
Of the nine respondents who reported that they "definitely will stop" before the trial, eight reduced their level to "definitely will not stop" after using Biotrue MPS for 2 weeks. Similarly, ten out of 18 of those who initially stated that they "probably will stop", and 29 out of 66 who initially stated there was a "slight chance" they would discontinue lens wear, reported they "definitely would not stop" wearing lenses following the study. Every subject who initially claimed they would "probably" or "definitely" stop wearing contact lenses lowered their likelihood of discontinuing lens wear at the end of the study.

Many of the patients in the study had taken prior measures to curb the likelihood with which they would discontinue contact lens wear. For example, some measures that patients reported included wearing contact lenses less often, switching contact lens brands, using rewetting drops, switching contact lens solution brands, using a contact lens solution more often, and/or switching contact lens type (ie, using daily disposable lenses versus monthly lenses).

When asked to compare Biotrue MPS to their current lens care brand, $86 \%$ of all subjects reported that Biotrue MPS made their lenses more comfortable and $87 \%$ stated their lenses felt moister throughout the day. When asked how Biotrue MPS compared to what was expected when they agreed to take part in the study, $89 \%$ of all subjects found their experience using the care system to be better than expected.

\section{Six-month follow-up results}

Online interviews were conducted with 73 of the study participants who responded to a follow-up survey 6 months after

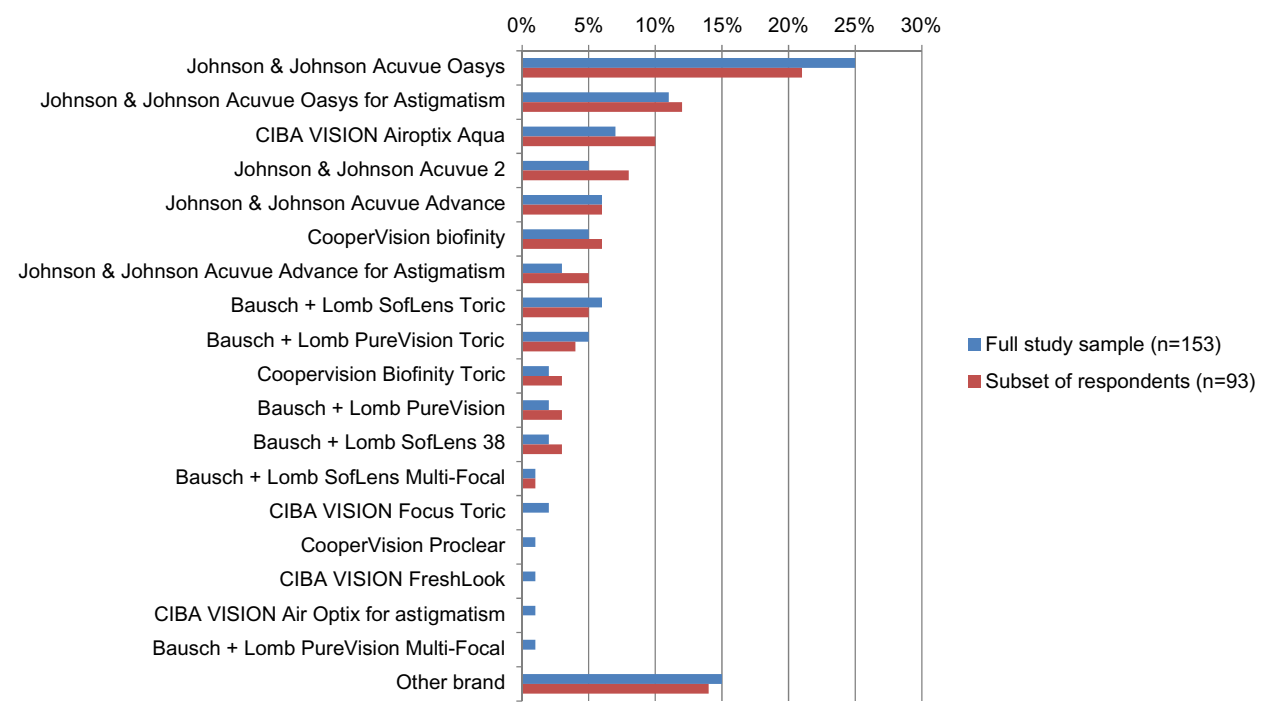

Figure I Breakdown of habitual lens brands worn by the subjects for both the full study sample and the subset of respondents.

Notes: Johnson \& Johnson Vision Care, Jacksonville, FL, USA; CIBA VISION, Fort Worth, TX, USA; CooperVision, Pleasanton, CA, USA; Bausch \& Lomb Incorporated, Rochester, NY, USA.

Abbreviation: $n$, number. 


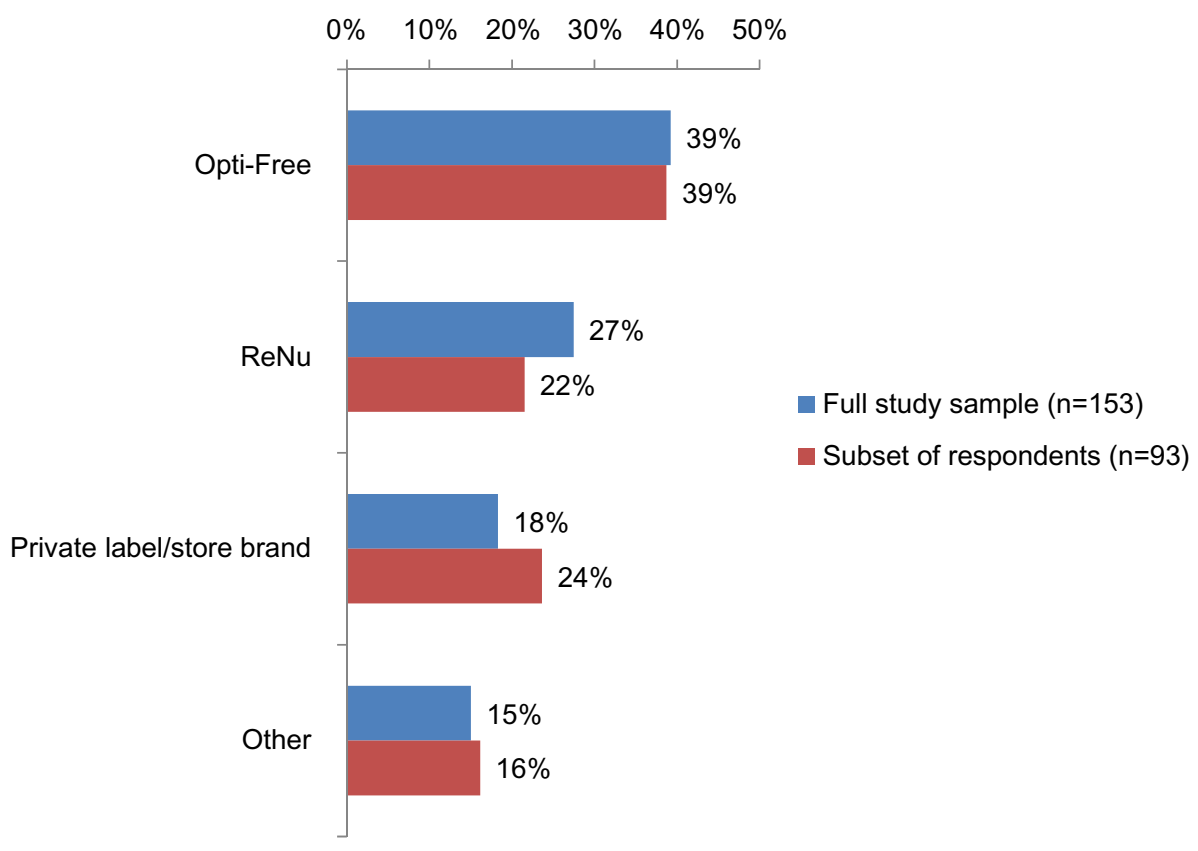

Figure 2 Breakdown of habitual lens care use prior to enrollment in the study for both the full study sample and the subset of respondents. Notes: Opti-Free, Alcon Laboratories, Inc, Fort Worth, TX, USA; Renu, Bausch \& Lomb Incorporated, Rochester, NY, USA.

Abbreviation: $\mathrm{n}$, number.

completion of the initial study. A total of $93 \%$ responded that they were still wearing contact lenses at least once per week. Of the $7 \%$ of respondents who were not currently wearing lenses 6 months after the initial study, two had dropped out of lens wear completely and three still wore lenses less than once per week. When asked again about their likelihood to discontinue contact lens wear, $86 \%$ had reduced their

Table 2 Change in the likelihood of dropping out of contact lens wear*

\begin{tabular}{|c|c|c|c|c|}
\hline & \multicolumn{2}{|c|}{$\begin{array}{l}\text { Likelihood of } \\
\text { dropping out } \\
\text { (among all subjects; } \\
n=93 \text { ) }\end{array}$} & \multirow{2}{*}{\multicolumn{2}{|c|}{$\begin{array}{l}\text { Likelihood of } \\
\text { dropping out } \\
\text { (among } n=84 \text { who } \\
\text { lowered their drop- } \\
\text { out propensity) }\end{array}$}} \\
\hline & \multirow[t]{2}{*}{ Pre-trial } & \multirow[t]{2}{*}{ Post-trial } & & \\
\hline & & & Pre-trial & Post-trial \\
\hline $\begin{array}{l}\text { Definitely will } \\
\text { not stop }\end{array}$ & $\begin{array}{l}\text { Screened } \\
\text { out }\end{array}$ & $51 \%$ & $\begin{array}{l}\text { Screened } \\
\text { out }\end{array}$ & $56 \%$ \\
\hline $\begin{array}{l}\text { Probably will } \\
\text { not stop }\end{array}$ & $\begin{array}{l}\text { Screened } \\
\text { out }\end{array}$ & $29 \%$ & $\begin{array}{l}\text { Screened } \\
\text { out }\end{array}$ & $32 \%$ \\
\hline $\begin{array}{l}\text { Might/might } \\
\text { not stop }\end{array}$ & $\begin{array}{l}\text { Not } \\
\text { included }\end{array}$ & $10 \%$ & $\begin{array}{l}\text { Not } \\
\text { included }\end{array}$ & $11 \%$ \\
\hline $\begin{array}{l}\text { Slight chance } \\
\text { I will stop }\end{array}$ & $71 \%$ & $8 \%$ & $68 \%$ & $1 \%$ \\
\hline Probably will stop & $19 \%$ & $2 \%$ & $21 \%$ & $0 \%$ \\
\hline Definitely will stop & $10 \%$ & $1 \%$ & $11 \%$ & $0 \%$ \\
\hline
\end{tabular}

Note: *Survey question: please use the scale below to indicate the likelihood of you stopping wearing contacts altogether in the next 6 months.

Abbreviation: $\mathrm{n}$, number. likelihood by at least one step in the continuum from pre-trial to 6 months post-trial.

After the initial 2-week trial, $81 \%$ of participants continued to use Biotrue MPS until the bottle was empty. Almost half of the original respondents (48\%) were using Biotrue MPS at the time of the 6-month follow-up (Figure 4).

\section{Discussion}

In 1983 , Berberian ${ }^{9}$ reported a dropout rate of $30 \%$ among newly fitted contact lens wearers in the course of a year (20\% for all new soft lens wearers and $40 \%$ for new gaspermeable lens wearers). Rumpakis ${ }^{1}$ conducted a Web-based survey in 27 countries to identify the contact lens dropout rate, the reasons associated with the discontinuation of lens wear, and the resulting economic impact. The author found that the discontinuation rate varied by country and ranged from $15.9 \%$ in the United States to $31 \%$ in Asia/Pacific Rim, which were similar to those rates found by Berberian ${ }^{9}$ 27 years earlier. Similar discontinuation rates were found by Pritchard et $\mathrm{al}^{8}$ (who found that $34 \%$ had discontinued lens wear at least once in 1999) and Richdale et $\mathrm{al}^{5}$ (who found that $24 \%$ of the sample had permanently discontinued contact lens wear in 2007). Contact lens discomfort is often cited as a major factor related to the discontinuation of contact lens wear. ${ }^{2-5,8}$ In the Rumpakis ${ }^{1}$ study, the top reasons for discontinuation were discomfort, poor vision, and expense, 


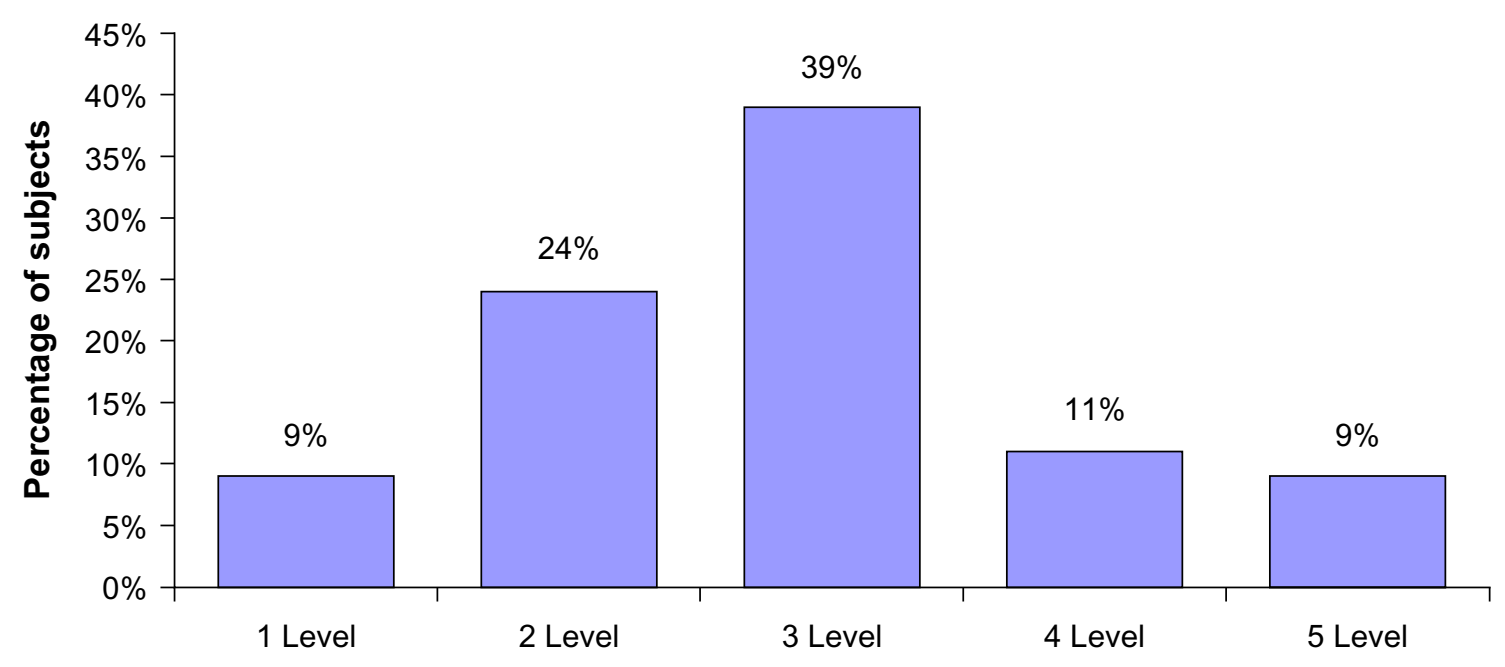

Figure 3 Percentage of subjects who lowered their propensity for discontinuation of lens wear by the number of levels lowered.

although inconvenience and fear of eye infections were common complaints amongst Asian patients.

Other researchers have found similar reasons for participants' discontinuation of lens wear. Weed et $\mathrm{al}^{3}$ surveyed 568 subjects in a study to determine the percentage of and reasons for discontinuation from contact lens wear. Of the 568 questionnaires that were returned, $51 \%$ of the subjects had discontinued contact lens wear. Twenty-seven (27\%) percent of the 144 participants who had resumed lens wear discontinued a second time. The most common reason for discontinuation was discomfort/irritation. In 1999, Pritchard et $a l^{8}$ reported on surveys received from 1,444 past or present contact lens wearers. The primary reason reported for the discontinuation of lens wear was discomfort or irritation ( $49 \%$ of the 488 patients who had discontinued lens wear at least once). The authors also reported that "improved comfort and relief of dryness were the primary factors that would improve contact lens wear for the group that had discontinued". 8

In a study of 236 lapsed contact lens wearers, Young et $a 1^{4}$ also reported discomfort as the primary reason for discontinuing lens wear in $51 \%$ of patients. The most common type of discomfort reported was dryness. More recently, Richdale et $\mathrm{al}^{5}$ reported on the specific patient factors and

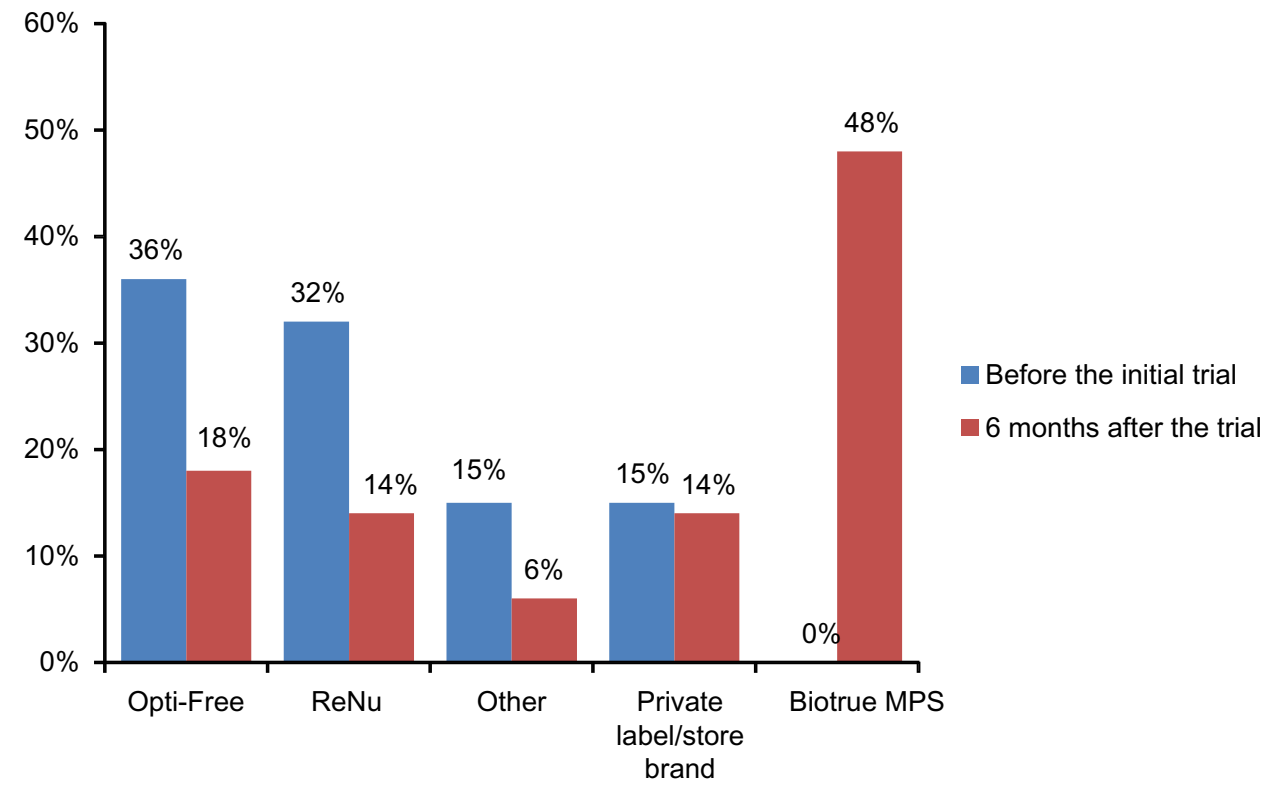

Figure 4 Breakdown of lens care use for the patients included in the 6-month follow-up visit $(n=73)$.

Notes: Opti-Free, Alcon Laboratories, Inc, Fort Worth, TX, USA; Renu and Biotrue, Bausch \& Lomb Incorporated, Rochester, NY, USA.

Abbreviation: $\mathrm{n}$, number. 
characteristics related to contact lens discontinuation. They too found that ocular symptoms of dryness and discomfort were the most frequently reported reasons for discontinuation. Furthermore, Evans et $\mathrm{al}^{2}$ also evaluated the factors related to discontinuation of silicone hydrogel contact lens wear. In their retrospective study, they found that patients who had discontinued lens wear reported a higher frequency of blurred vision, discomfort, lens awareness, burning and stinging, dryness, and redness.

With respect to symptoms of dryness and discomfort in the present study, $86 \%$ of all subjects reported that Biotrue MPS made their lenses more comfortable, and 87\% stated that their lenses felt moister throughout the day. It is hypothesized that the reduction of these key symptoms played a role in the reduced propensity for contact lens wear discontinuation in our study. Biotrue MPS contains wetting agents, which can reduce the surface tension of a lens, helping moisture to spread easier across the lens. ${ }^{11,12}$ The longer the wetting agents stay associated with the lens, the longer they may help to keep the lenses moist. ${ }^{13}$ One such conditioning polymer found in Biotrue MPS is hyaluronan, a natural lubricant found throughout the human body, including in tears ${ }^{14}$ and in the corneal epithelium. ${ }^{15}$ Previous studies have shown the release of hyaluronan in both traditional hydrogel and silicone hydrogel contact lenses over a 20 -hour time period. ${ }^{16}$

Although discomfort and dryness are often cited as the primary reasons for contact lens drop out, product-related reasons are also noted. In the previously mentioned study by Young et $\mathrm{al}^{4}$ - who investigated 236 lapsed wearers who were refitted into contact lenses - the investigators concluded that some of the previous discontinuations were related to product performance. While the investigators agreed with the subjects' assessments of their own reasons for discontinuing contact lens wear, they also ranked up to three factors they believed were likely to contribute to the discontinuation of lens wear. The greatest difference between investigators' and patients' main reasons cited for contact lens discontinuation was related to care product performance. Although nonavailability of appropriate lenses was the main factor cited by investigators, they cited the care system as a factor in $10 \%$ of cases. In a study of multipurpose care systems, Stiegemeier et $\mathrm{al}^{17}$ stated that "Selecting an appropriate lens care product enhances patients' wearing experience, maintains optimal lens performance and may help to prevent drop-out". Similarly, in his 2010 study, Rumpakis ${ }^{1}$ concluded that "because the most frequently reported reason for dropout is discomfort, eye care practitioners should select contact lenses and lens care products that increase comfort and provide good cleaning and disinfection".

The present study highlights the importance of selecting the appropriate lens care products. After using Biotrue MPS for 2 weeks, $90 \%$ of the soft contact lens wearers who were enrolled in the study reduced their likelihood of discontinuing contact lens wear by at least one level, with many showing reductions by several levels. Approximately half of the patients indicated that their likelihood of discontinuing lens wear had dropped to "definitely will not stop" wearing lenses following the study, and at the 6-month follow-up, $93 \%$ of patients were still wearing contact lenses at least once per week.

\section{Conclusion}

When patients intending to drop out of contact lens wear due to discomfort and dryness were switched to Biotrue MPS, a significant reduction in the propensity for discontinuing lens wear was observed. Six months after completion of the study, $93 \%$ of patients were still wearing contact lenses at least once per week.

\section{Acknowledgments}

This study was funded by Bausch \& Lomb Incorporated.

\section{Disclosure}

All authors were employees of Bausch \& Lomb Incorporated at the time of writing this manuscript. The authors report no other conflicts of interest in this work.

\section{References}

1. Rumpakis J. New data on contact lens dropouts: an international perspective. Review of Optometry. 2010. Available from http://www. revoptom.com/content/d/contact_lenses/i/990/c/18929/. Accessed December 6, 2013

2. Evans VE, Carnt NA, Naduvilath TJ, Holden BA. Factors associated with drop out from silicone hydrogel contact lens daily wear. Invest Ophthalmol Vis Sci. 2008;49:E-Abstract 4839.

3. Weed KH, Fonn D, Potvin R. Frequent replacement of soft contact lenses reduces complications: 2 year results. Poster presented at: American Academy of Optometry Annual Meeting; 1993. Available from http:// member.aaopt.org/library/frameTemplate.asp?pageurl=/Submission/ Search/ArchiveSubmissionViewer.asp?ASID=4024\&pageType=print. Accessed December 6, 2013.

4. Young G, Veys J, Pritchard N, Coleman S. A multi-centre study of lapsed contact lens wearers. Ophthalmic Physiol Opt. 2002;22(6):516-527.

5. Richdale K, Sinnott LT, Skadahl E, Nichols JJ. Frequency of and factors associated with contact lens dissatisfaction and discontinuation. Cornea. 2007;26(2):168-174.

6. Chalmers RL, McNally JJ, McKenney CD, Robirds SR. The role of dryness symptoms in discontinuation of wear and unscheduled lens removals in extended wear of silicone hydrogel lenses. Invest Ophthalmol Vis Sci. 2002;43:E-Abstract 3088.

7. Young G. Why one million contact lens wearers dropped out. Cont Lens Anterior Eye. 2004;27(2):83-85. 
8. Pritchard N, Fonn D, Brazeau D. Discontinuation of contact lens wear: a survey. Int Contact Lens Clin. 1999;26(6):157-162.

9. Berberian D. The contact lens 'drop-out' - a dissatisfied person? Ophthalmic Optician. 1983;17:551.

10. Schlanger JL. A study of contact lens failures. J Am Optom Assoc. 1993;64(3):220-224.

11. Bennett ES, Weissman BA. Clinical Contact Lens Practice. Philadelphia, PA: Lippincott Williams \& Wilkins; 2005.

12. Rosen MJ. Reduction of surface and interfacial tension by surfactants. In: Surfactants and Interfacial Phenomena. John Wiley \& Sons, Inc; New York, NY. 1978:207-239.

13. Burke SE, Scheuer CA, Doty KC, Fridman KM, Liranso T. Retention and release of the wetting agent combination found in a novel multi-purpose solution from hydrogel and silicone hydrogel contact lenses. Optom Vis Sci. 2011;88:E-abstract 115701. Available at http://member.aaopt. org/Submission/Search/SubmissionViewer.asp?SID=28701\&BR=SP. Accessed December 6, 2013.
14. Frescura M, Berry M, Corfield A, Carrington S, Easty DL. Evidence of hyaluronan in human tears and secretions of conjunctival cultures. Biochem Soc Trans. 1994;22(2):228S.

15. Lerner LE, Schwartz DM, Hwang DG, Howes EL, Stern R. Hyaluronan and CD44 in the human cornea and limbal conjunctiva. Exp Eye Res. 1998;67(4):481-484.

16. Scheuer CA, Fridman KM, Barniak VL, Burke SE, Venkatesh S. Retention of conditioning agent hyaluronan on hydrogel contact lenses. Cont Lens Anterior Eye. 2010;33(1):S2-S6.

17. Stiegemeier MJ, Friederichs GJ, Hughes JL, Larsen S, Movic W, Potter WB. Clinical evaluation of a new multi-purpose disinfecting solution in symptomatic contact lens wearers. Cont Lens Anterior Eye. 2006;29(3):143-151.
Clinical Ophthalmology

\section{Publish your work in this journal}

Clinical Ophthalmology is an international, peer-reviewed journal covering all subspecialties within ophthalmology. Key topics include: Optometry; Visual science; Pharmacology and drug therapy in eye diseases; Basic Sciences; Primary and Secondary eye care; Patien Safety and Quality of Care Improvements. This journal is indexed on

Submit your manuscript here: http://www.dovepress.com/clinical-ophthalmology-journal

\section{Dovepress}

PubMed Central and CAS, and is the official journal of The Society of Clinical Ophthalmology (SCO). The manuscript management system is completely online and includes a very quick and fair peer-review system, which is all easy to use. Visit http://www.dovepress.com/ testimonials.php to read real quotes from published authors. 